\title{
Increased levels of osteopontin in sputum supernatant in severe refractory asthma
}

\author{
Vasiliki Delimpoura, ${ }^{1}$ Petros Bakakos, ${ }^{2}$ Eleni Tseliou, ${ }^{1}$ Vasiliki Bessa, ${ }^{1}$ Georgios Hillas, ${ }^{3}$ \\ Davina CM Simoes, ${ }^{4}$ Spyros Papiris, ${ }^{1}$ Stelios Loukides ${ }^{1}$
}

${ }^{1}$ 2nd Respiratory Medicine Department, University of Athens Medical School,

"Attikon" Hospital, Athens, Greece

${ }^{2} 1$ st Respiratory Medicine Department, University of Athens Medical School,

"Sotiria" Chest Hospital, Athens, Greece

${ }^{3}$ Department of Respiratory and Critical Care Medicine, Research Unit, "Sotiria" Chest Hospital, Athens, Greece

${ }^{4} \mathrm{G}$ P Livanos and M Simou Laboratories, "Evangelismos" Hospital, Department of Critical Care and Pulmonary Services, University of Athens, Medical School, Athens, Greece

\section{Correspondence to}

Stelios Loukides, 2nd

Respiratory Medicine Department, University of Athens Medical School, "Attikon" Hospital, Smolika 2 16673, Athens, Greece; ssat@hol.gr

Received 12 March 2010 Accepted 23 May 2010

\begin{abstract}
Background Osteopontin (OPN) is a glycoprotein that has been associated with inflammation and fibrosis. Severe refractory asthma (SRA) is characterised by an intense inflammatory and remodelling process. The aim of this study was to investigate the levels of OPN in sputum supernatants of patients with SRA, to compare them with milder forms of the disease and to investigate their possible association with mediators and cells involved in the inflammatory and remodelling process. Methods 33 patients with SRA, 29 with moderate asthma, 21 with steroid-naïve asthma and 20 healthy subjects were studied. All subjects underwent lung function tests, bronchial hyper-responsiveness assessment and sputum induction for cell count identification and measurement of OPN, vascular endothelial growth factor, transforming growth factor $\beta 1$ (TGF- $\beta 1$ ), cysteinyl leukotrienes, interleukin 13 (IL-13), eosinophilic cationic protein (ECP) and IL-8 in sputum supernatants.
\end{abstract}

Results Median (IQR) OPN levels (pg/ml) were significantly higher in patients with SRA than in those with moderate asthma, steroid-naive asthma and healthy control subjects (1840 (1125-11000) vs 130 $(100-210)$ vs $100(67-130)$ vs $50(42-70)$, respectively, $\mathrm{p}<0.001)$. Regression analysis showed a significant association between log OPN and sputum eosinophils, cysteinyl leukotrienes, IL-13, TGF- $\beta 1$ and ECP. TGF- $\beta 1$ represented the strongest association with OPN. The above associations were not observed in milder forms of the disease or in healthy subjects. Conclusions The results indicate that OPN levels are higher in SRA than in less severe forms of the disease. Moreover, OPN is associated with mediators involved in both the inflammatory and remodelling process such as TGF- $\beta 1$, IL-13 and cysteinyl leukotrienes only in SRA.

\section{INTRODUCTION}

Asthma is characterised by eosinophilic airway inflammation. Several mechanisms are involved in its pathogenesis, such as enhancement of the Th2 immune response, migration of eosinophils into the airways, airway mucus production and airway remodelling. ${ }^{1}$ A range of inflammatory mediators is involved in airway remodelling. Transforming growth factor $\beta 1$ (TGF- $\beta 1$ ) is expressed in the airways of patients with asthma, stimulates fibroblasts to produce extracellular matrix (ECM) proteins (collagen, fibronectin) and plays an important role in airway smooth muscle proliferation. ${ }^{1}$ Moreover, TGF- $\beta 1$ is probably involved in the dysregulated epithelial repair of asthmatic airways possibly through the induction of epithelial mesen- chymal transition of airway epithelial cells. ${ }^{2}$ Additionally, vascular endothelial growth factor (VEGF) is one of the most potent pro-angiogenic factors and it induces vascular endothelial cell proliferation, migration and tubule formation. ${ }^{3}$ Interleukin-13 (IL-13) is a Th2 cytokine that has emerged as a critical regulator of inflammatory immune responses with a key role in asthma remodelling. ${ }^{3}$

Severe refractory asthma (SRA) may present with different inflammatory cellular profiles. ${ }^{4}$ Amplified inflammatory and structural and/or remodelling changes in the airways may account for the poor steroid response of patients with SRA. ${ }^{4}{ }^{5}$ Osteopontin (OPN) is a phosphorylated acidic glycoprotein that can function both as an ECM molecule and a cytokine. ${ }^{6}$ It has been associated with tissue remodelling since it promotes proliferation and migration of both murine smooth muscle cells and fibroblasts and stimulates the production of collagen. ${ }^{7} 8$ Moreover, OPN can mediate interactions between cells and ECM, recruit $T$ cells, stimulate Th1 cytokine expression and promote angiogenesis. ${ }^{9} 10$ Epithelial cells, macrophages, $\mathrm{T}$ cells and fibroblasts have been shown to express OPN. ${ }^{11-13}$

Increased levels of OPN have been found in biological fluids of patients with asthma. ${ }^{6} 14$ Interestingly, in one of the above studies OPN levels in bronchoalveolar lavage (BAL) fluid were significantly correlated with fibrotic changes. ${ }^{6}$ In patients with asthma OPN is upregulated in bronchial epithelial cells and macrophages. ${ }^{15}$ Moreover, OPN seems to play a role in the migration of eosinophils into the asthmatic airways. ${ }^{14}$ Finally, animal studies show that OPN is increased in allergeninduced chronic airway remodelling, whereas its deficiency protects against airway remodelling and bronchial hyper-responsiveness (BHR). ${ }^{16}$

The aim of the present study was to measure OPN levels in sputum supernatants of patients with asthma of different underlying severity and healthy controls. We hypothesised that sputum OPN levels would be higher in patients with SRA than in those with milder forms of the disease, and that it would be associated with inflammatory cells and mediators involved in the ongoing airway inflammation and remodelling process in severe asthma.

\section{MATERIALS AND METHODS \\ Subjects}

Patients were recruited from an open cohort of patients with asthma who were followed up in the asthma clinics of the 1st and 2nd Respiratory Medicine University Departments in Athens for at least 2 years. The diagnosis of asthma was established 
according to the Global Initiative for Asthma (GINA) guidelines ${ }^{17}$ and the diagnosis of SRA was established according to American Thoracic Society criteria. ${ }^{18}$ Thirty-three patients with SRA were finally recruited, as well as 29 patients with moderate asthma and 21 patients with mild intermittent (steroid-naïve) asthma diagnosed according to the 2005 GINA classification. ${ }^{17}$ The patients with mild intermittent asthma had been asymptomatic for at least 3 months before entering the study. All the patients with asthma were non-smokers. Twenty healthy non-atopic non-smoking subjects comprised the control group. Subjects with any other respiratory disease or any concomitant malignant, heart, renal, liver or collagen disease were excluded. Patients with a respiratory tract infection or asthma exacerbation in the past 8 weeks prior to admission were also excluded.

\section{Induced sputum}

Sputum was induced as previously described ${ }^{19}$ using all the modifications for safe measurements according to the underlying asthma severity. ${ }^{20}$ Briefly, patients inhaled 3\% saline at room temperature nebulised by an ultrasonic nebuliser (DeVilbiss Co, Heston, UK) at the maximal saline output ( $4 \mathrm{ml} / \mathrm{min})$. The total period of sputum induction was $15 \mathrm{~min}$. Subjects were encouraged to cough deeply at $3 \mathrm{~min}$ intervals until the $15 \mathrm{~min}$ induction time had been completed. Sputum was processed using selected plugs as previously described. ${ }^{21}$ Dithiothreitol was added in a volume equal to four times the weight of the sputum specimen and it was further diluted with phosphate buffered saline in a volume equal to the sputum plus dithiothreitol. Total cell counts were performed on a haemacytometer using Trypan blue stain. Slides were prepared by using cytospin (Shandon, Runcorn, UK) and were stained with May-Grunwald and Giemsa for differential cell counts. Cell counting was performed by an observer blind to the clinical characteristics of the subjects. At least 500 inflammatory cells were counted in each sample. A sample was considered adequate when the patient was able to expectorate at least $2 \mathrm{ml}$ of sputum and the slides contained $<10 \%$ squamous cells on differential cell counting. The total cell count (expressed as the number of cells $\times 10^{6}$ ) and the percentage of sputum inflammatory cells were used for analysis. Sputum supernatants were kept at $-70{ }^{\circ} \mathrm{C}$ for further measurement of IL-8, IL-13, eosinophilic cationic protein (ECP), cysteinyl leukotrienes, OPN, VEGF and TGF- $\beta 1$.

\section{Lung function}

Forced expiratory volume in $1 \mathrm{~s}\left(\mathrm{FEV}_{1}\right)$, forced vital capacity (FVC), $\mathrm{FEV}_{1} / \mathrm{FVC}$ ratio, static volumes (functional residual capacity) and carbon monoxide transfer factor (TLCO) were measured using Master Screen Body (Viasys Healthcare, Jaeger, Hoechberg, Germany) according to the American Thoracic Society guidelines. ${ }^{22}$

\section{Bronchial hyper-responsiveness}

BHR was measured as the dose of methacholine provoking a fall in $\mathrm{FEV}_{1}$ of $\geq 15 \%\left(\mathrm{PD}_{15}\right)$ using a commercially available system (APS; Viasys Healthcare, Jaeger) according to American Thoracic Society guidelines. ${ }^{23}$

\section{Measurement of fraction of exhaled nitric oxide}

Fraction of exhaled nitric oxide (FeNO) was measured using a portable nitric oxide analyser (NIOX MINO Airway Inflammation Monitor; Aerocrine, Solna, Sweden) as previously described. ${ }^{24}$

\section{Atopic status}

A positive skin prick test to any of 20 common aeroallergens (including mites, grasses, trees, fungus, domestic animals) was used to confirm atopy.

\section{Mediator assays}

ECP was measured using Unicap ECP kit (Pharmacia Diagnostics; Uppsala, Sweden) with a detection limit of $0.5 \mathrm{ng} / \mathrm{ml}$. VEGF, IL-13 and IL-8 were measured using an ELISA kit (R\&D Systems, Minneapolis, Minnesota, USA) with detection limits of $9 \mathrm{pg} / \mathrm{ml}, 32 \mathrm{pg} / \mathrm{ml}$ and $3.5 \mathrm{pg} / \mathrm{ml}$, respectively. Cysteinyl leukotrienes were measured using an ELISA kit (Cayman Chemical; Ann Arbor, Michigan, USA) with a detection limit of $13 \mathrm{pg} / \mathrm{ml}$. TGF- $\beta 1$ and human OPN were measured by ELISA kits (R\&D Systems) with lower detection limits of $50 \mathrm{pg} / \mathrm{ml}$ and $6 \mathrm{pg} / \mathrm{ml}$, respectively. All values were expressed as $\mathrm{pg} / \mathrm{ml}$. The intra-assay and interassay variability were assessed according to the manufacturers' instructions for all the mediators measured and were within acceptable coefficient of variation (\%). For OPN, the intra-assay and interassay variabilities were $4 \%$ and $6.5 \%$, respectively. The recovery and linearity of the assays after appropriate spiking experiments produced samples with values within the dynamic range of the assay.

\section{Study design}

On day 1 all subjects underwent medical history and physical examination by an experienced respiratory physician, lung function measurements, measurement of body mass index (BMI), FeNO measurement, BHR assessment and skin prick tests. The day after, sputum induction was performed.

\section{Statistical analysis}

Normally distributed data are presented as mean \pm SD whereas skewed data are presented as median (IOR). Normality of distribution was checked with the Kolmogorov-Smirnov test. Statistical comparisons between groups were performed with one-way analysis of variance (ANOVA) for normally distributed data and with the Kruskal-Wallis tests for skewed data, accompanied by appropriate post hoc tests for multiple comparisons (Bonferroni and Dunn's, respectively). Differences in numerical variables within two groups were evaluated with unpaired tests or with Mann-Whitney $U$ tests for normally and skewed data, respectively, whereas comparisons of proportions were performed using $\chi^{2}$ tests. In order to examine the association between OPN, inflammatory and remodelling mediators (ECP, IL-8, cysteinyl leukotrienes, IL-13, VEGF, TGF$\beta 1)$, sputum cells and lung function tests, linear regression analysis was performed using OPN as the dependent variable. All linear regressions were performed in a combined model for all asthma groups after proper adjustments for age, gender, BMI, atopy, duration of the disease and treatment regimens. Data were interpreted as standardised coefficients with 95\% CIs. Values which were not normally distributed were log-transformed to obtain normal distribution for regression analysis. A $p$ value $<0.05$ (two-sided) was considered significant. Statistical analysis was performed using SPSS 16.0 (SPSS Inc; Chicago, Illinois, USA) and Graph Pad Prism 5 (Graphpad Software; California, USA).

\section{RESULTS}

\section{Demographic characteristics}

The demographic characteristics of the study patients are summarised in table 1.

Patients with SRA were all receiving $>1200 \mu$ g budesonide/ day or equivalent plus long-acting $\beta_{2}$ agonists (LABA), whereas patients with moderate asthma were receiving $<800 \mu \mathrm{g}$ budesonide/day or equivalent plus LABA. Among the patients with SRA, 17 were also receiving $5 \mathrm{mg}$ prednisolone/day while 4 were 
Table 1 Demographic characteristics of study subjects

\begin{tabular}{|c|c|c|c|c|c|}
\hline Variables & SRA $(n=33)$ & $\begin{array}{l}\text { Moderate } \\
\text { asthma }(n=29)\end{array}$ & $\begin{array}{l}\text { Naïve } \\
\text { asthma }(n=21)\end{array}$ & $\begin{array}{l}\text { Normal } \\
\text { subjects }(n=20)\end{array}$ & p Value \\
\hline Age (years) & $54 \pm 13$ & $51 \pm 17$ & $55 \pm 9$ & $52 \pm 10$ & 0.825 \\
\hline Gender (F/M) & $21 / 12$ & $16 / 10$ & $12 / 9$ & $11 / 9$ & 0.650 \\
\hline Atopy & $19 / 33$ & $17 / 29$ & $12 / 21$ & 0 & 0.726 \\
\hline Duration of disease (years) & $37(31-44)$ & $31(27-38)$ & $32(26-37)$ & ND & 0.345 \\
\hline BMI $\left(\mathrm{kg} / \mathrm{m}^{2}\right)$ & $28 \pm 5$ & $27 \pm 4$ & $27 \pm 4$ & $26 \pm 4$ & 0.720 \\
\hline FeNO (ppb) & $21(18-61)$ & $19(16-44)$ & $34(17-74)$ & $12(10-13)$ & $0.003 \dagger$ \\
\hline $\mathrm{BHR}\left(\mathrm{PD}_{15}, \mathrm{mg}\right)$ & $0.08 \pm 0.03$ & $0.15 \pm 0.06$ & $0.2 \pm 0.09$ & $>2$ & $0.005^{*}$ \\
\hline $\mathrm{FEV}_{1}(\%$ predicted $)$ & $66(55-73)$ & $81(76-108)$ & $86(73-97)$ & $94(85-98)$ & $0.001^{*}$ \\
\hline $\mathrm{PB} \mathrm{FEV}_{1}$ (\% predicted) & $72(59-84)$ & $93(84-114)$ & $90(81-98)$ & $95(88-99)$ & $0.003^{*}$ \\
\hline FVC (\% predicted) & $87 \pm 17$ & $101 \pm 16$ & $95 \pm 11$ & $96 \pm 10$ & $0.005^{*}$ \\
\hline $\mathrm{FEV}_{1} / \mathrm{FVC}(\%)$ & $63 \pm 7$ & $71 \pm 7$ & $72 \pm 8$ & $87 \pm 6$ & $0.001^{*}$ \\
\hline TLco (\% predicted) & $77 \pm 12$ & $88 \pm 10$ & $92 \pm 7$ & $95 \pm 6$ & $0.003^{*}$ \\
\hline FRC ( $\%$ predicted) & $110 \pm 23$ & $97 \pm 15$ & $90 \pm 12$ & $89 \pm 12$ & $0.001^{*}$ \\
\hline \multicolumn{6}{|l|}{ Treatment regimens } \\
\hline ICS (number-dose $\ddagger$ ) & $33-1440$ & $29-640$ & 0 & 0 & \\
\hline LABA & 33 & 29 & 0 & 0 & \\
\hline Oral CS & 21 & 0 & 0 & 0 & \\
\hline Omalizumab/LTRA & $5 / 12$ & $0 / 8$ & 0 & 0 & \\
\hline
\end{tabular}

Normally distributed data are presented as mean \pm SD and skewed data are presented as median (IOR).

* Significant $p$ values pertaining to differences among the four groups all in favour of SRA.

†Significant $\mathrm{p}$ values pertaining to differences among the four groups in favour of those with steroid-naïve asthma.

$\neq$ Dose expressed as equivalent to budesonide in $\mu \mathrm{g}$.

BMI, body mass index; BHR, bronchial hyper-responsiveness; CS, corticosteroids; FeNO, fraction of exhaled nitric oxide; FEV , forced expiratory volume in 1 s; FRC, functional residual capacity;

FVC, forced vital capacity; ICS, inhaled corticosteroids; LABA, long-acting $\beta_{2}$ agonists; LTRA, leukotriene receptor antagonists; PB FEV ${ }_{1}$, postbrochodilation forced expiratory volume in 1 s;

SRA, severe refractory asthma; TLCO, carbon monoxide transforming factor.

receiving $7.5 \mathrm{mg}$ prednisolone/day. The 5 patients receiving omalizumab were all on their fourth month of anti-IgE treatment. In the SRA group, 11 patients did not undergo BHR measurement because the $\mathrm{FEV}_{1}$ was $<60 \%$ of predicted. Sputum induction was well tolerated by all patients.

\section{Inflammatory variables in induced sputum according to asthma severity}

The inflammatory variables of the study patients are summarised in table 2. OPN was undetectable in five healthy subjects, three patients with steroid-naïve asthma and one patient with moderate asthma; TGF- $\beta 1$ was undetectable in four healthy subjects and two patients with steroid-naïve asthma; and IL-13 was undetectable in six healthy subjects, three patients with steroid-naive asthma, two patients with moderate asthma and two patients with SRA.

OPN levels $(\mathrm{pg} / \mathrm{ml})$ were significantly higher in patients with SRA than in patients with moderate asthma, those with steroid- naive asthma or healthy control subjects $(\mathrm{p}<0.001$, table 2 , figure $1(\log$ scale)). Patients with moderate asthma had significantly higher OPN levels than steroid-naïve patients and healthy subjects $(p=0.01)$. A significant difference in OPN levels was observed between steroid-naïve patients and healthy subjects in favour of those with steroid-naive asthma $(p=0.04)$. OPN levels in patients with SRA treated with oral steroids $(n=21$, age $54 \pm 14$ years) did not significantly differ from levels in those not receiving oral steroids ( $n=12$, age $=53 \pm 15$ years), (median (IOR) 1800 (727-10575) vs 2960 (1330-11800), $\mathrm{p}=0.635$ ).

Inflammatory mediators (IL-8, ECP, cysteinyl leukotrienes) and mediators involved in airway remodelling (VEGF, TGF- $\beta 1$, IL-13) were significantly higher in patients with SRA than in the other three groups (table 2). With the exception of VEGF levels, all the remaining mediators were significantly higher in patients with moderate asthma than in those with steroid-naïve asthma and healthy subjects $(\mathrm{p}<0.05$ for all comparisons, table 2$)$.

Table 2 Inflammatory variables of study subjects

\begin{tabular}{|c|c|c|c|c|c|}
\hline Variables & SRA $(n=33)$ & Moderate asthma $(n=29)$ & Naïve asthma $(n=21)$ & Normal subjects $(n=20)$ & p Value \\
\hline Cells $\left(\times 10^{6} / \mathrm{ml}\right)$ & $2.9(0.9-3.5)$ & $1.7(1-2.4)$ & $1(0.7-1.6)$ & $0.8(0.6-1.1)$ & $0.002^{*}$ \\
\hline Eosinophils (\%) & $11(4-19)$ & $6(3-9)$ & $4(1-7)$ & $0.5(0-1)$ & $<0.001^{*}$ \\
\hline Neutrophils (\%) & $40(28-46)$ & $22(20-42)$ & $25(44-40)$ & $23(17-25)$ & $0.002^{*}$ \\
\hline Lymphocytes (\%) & $2(1-3)$ & $2(1-3)$ & $0.4(0-1)$ & $0.25(0-1)$ & 0.756 \\
\hline OPN (pg/ml) & $1840(1125-11000)$ & $130(100-210)$ & $100(67-130)$ & $50(42-70)$ & $<0.001^{*}$ \\
\hline VEGF (pg/ml) & $1212(882-1555)$ & $400(300-450)$ & $564(389-654)$ & $210(202-223)$ & $<0.001^{*}$ \\
\hline IL-8 (pg/ml) & $2090(730-3500)$ & $1670(1350-1920)$ & $670(550-1200)$ & $432(314-556)$ & $<0.001^{*}$ \\
\hline CystLts (pg/ml) & $243(207-334)$ & $121(109-148)$ & $121(96-125)$ & $93(75-121)$ & $<0.001^{*}$ \\
\hline IL-13 (pg/ml) & $180(73-228)$ & $68(48-87)$ & $54(47-60)$ & $34(33-38)$ & $<0.001^{*}$ \\
\hline
\end{tabular}

Data presented as median (IQR).

* Significant $p$ values pertaining to differences among the four groups, all in favour of SRA

CystLts, cysteinyl leukotrienes; ECP, eosinophilic cationic protein; IL-8, interleukin 8; IL-13, interleukin-13; OPN, osteopontin; SRA, severe refractory asthma; TGF- $\beta 1$, transforming growth factor $\beta$; VEGF, vascular endothelial growth factor. 


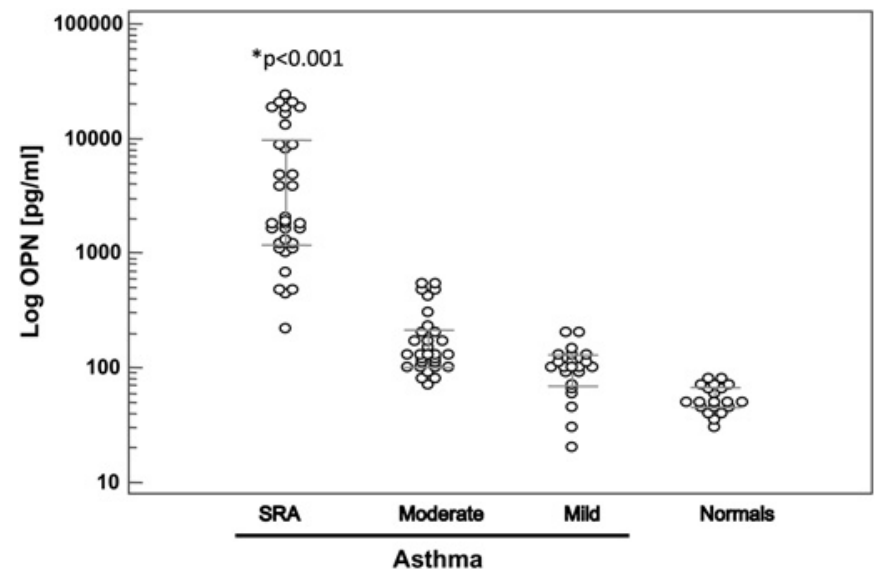

Figure 1 Osteopontin values ( $\log$ scale, $\mathrm{pg} / \mathrm{ml}$ ) in patients with severe refractory asthma (SRA), moderate asthma, steroid-naïve asthma and normal subjects. ${ }^{*} p<0.001$ in favour of SRA.

\section{Associations of osteopontin}

After applying the adjustments mentioned above, log OPN levels presented a significant positive association with sputum eosinophils $(p=0.006)$. Significant positive associations were also observed between log OPN levels and cysteinyl leukotrienes, IL13, ECP and TGF- $\beta 1$ levels in patients with SRA (table 3). Stepwise regression analysis showed that TGF- $\beta 1$ represented the strongest association with OPN $(p<0.001)$. No significant associations were observed between logOPN levels and the remaining inflammatory cells and mediators in SRA.

There were no significant associations between OPN levels, inflammatory and/or remodelling mediators or sputum inflammatory cells in patients with moderate asthma, steroidnaive asthma and healthy subjects, with the exception of a significant association between IL-13 levels and log OPN in moderate asthma $(\mathrm{p}=0.04)$. No significant association was observed between OPN and BHR in all asthma groups. Finally, no significant associations were observed between OPN levels and lung function tests.

Table 3 Regression analysis between log OPN, inflammatory cells, mediators and lung function tests in patients with SRA

\begin{tabular}{llcr}
\hline Variables & $\begin{array}{l}\boldsymbol{\beta} \text { standardised } \\
\text { coefficient (95\% Cl) }\end{array}$ & Adjusted $\mathbf{R}^{2}$ & $\boldsymbol{p}$ Value \\
\hline Total cells $\left(\times 10^{6} / \mathrm{ml}\right)$ & $0.12(-943$ to 1642$)$ & 0.05 & 0.614 \\
Eosinophils (\%) & $0.6(128$ to 580$)$ & 0.27 & 0.006 \\
Neutrophils (\%) & $0.16(-140$ to 284$)$ & -0.02 & 0.506 \\
Macrophages (\%) & $-0.22(-289$ to 101$)$ & -0.001 & 0.355 \\
Lymphocytes (\%) & $0.07(-1911$ to 2557$)$ & -0.002 & 0.812 \\
IL-8 (pg/ml) & $-0.23(-51$ to 17$)$ & 0.03 & 0.314 \\
ECP (pg/ml) & $0.6(839$ to 3847$)$ & 0.4 & 0.001 \\
CystLts (pg/ml) & $0.45(2$ to 64$)$ & 0.39 & 0.004 \\
IL-13 (pg/ml) & $0.68(27$ to 85$)$ & 0.45 & 0.001 \\
TGF- $\beta 1$ (pg/ml) & 0.82 (576 to 1144$)$ & 0.68 & $<0.001$ \\
VEGF (pg/ml) & $-0.19(-9$ to 4$)$ & 0.03 & 0.450 \\
FEV $1 \%$ predicted) & $-0.01(-220$ to 210$)$ & -0.05 & 0.820 \\
FEV $/$ FVC (\% predicted) & $0.08(-402$ to 560$)$ & 0.04 & 0.723 \\
FRC (\% predicted) & $-0.2(-239$ to 50$)$ & 0.04 & 0.215 \\
TLCo (\% predicted) & 0.09 (-290 to 301$)$ & -0.05 & 0.832 \\
\hline
\end{tabular}

Regression analysis was performed after proper adjustments for age, gender, body mass index, atopy and treatment regimens. Non-normally distributed data were logarithmically transformed.

CystLts, cysteinyl leukotrienes; ECP, eosinophilic cationic protein; $\mathrm{FEV}_{1}$, forced expiratory volume in $1 \mathrm{~s}$; FRC, functional residual capacity; FVC, forced vital capacity; IL-8, interleukin 8; IL-13, interleukin-13; OPN, osteopontin; SRA, severe refractory asthma; TGF- $\beta 1$, transforming growth factor $\beta$; TLCO, carbon monoxide transfer factor; VEGF, vascular endothelial growth factor.

\section{DISCUSSION}

The novel finding of the present study is that OPN levels in sputum supernatants of patients with SRA are significantly higher than in patients with milder forms of the disease and healthy subjects. Additionally, OPN is positively associated with inflammatory cells and mediators involved in the ongoing airway inflammation and the remodelling process (ie, eosinophils, ECP, cysteinyl leukotrienes, IL-13 and TGF- $\beta 1$ ) in patients with SRA but not in those with milder forms of the disease.

Previous studies have found increased levels of OPN in induced sputum and BAL fluid in patients with asthma compared with controls. ${ }^{14} 25$ However, OPN levels in induced sputum of patients with asthma were not related to underlying severity. Our results are partially in agreement with the above findings, suggesting a specific role for OPN in SRA. The main differences between our study and previous ones are the larger number of patients included and the accurate definition of severe asthma which is based on established criteria.

The extremely low OPN levels in mild and moderate asthma and the high percentage of undetectable OPN levels in normal subjects might be attributed to the absence and/or inactivation of OPN-producing cells. In accordance with our finding, a previous study showed that no OPN expression was found in tissue sections of a limited number of non-asthmatic control subjects. ${ }^{6}$ Previous in vitro studies have shown that OPN is produced by fibroblasts as well as by several murine immune cell types such as macrophages, T cells, B cells and mast cells. ${ }^{13} 2627$ We were unable to identify the cells responsible for OPN production in the current study since the inflammatory cells assessed by induced sputum reflect the cellular content of the lower airway lining fluid and not the subepithelial layers that seem to represent the basic cellular source of OPN. ${ }^{6} 15$

With regard to the association of OPN levels with the percentage of eosinophils in SRA observed in our study, it is quite unlikely that eosinophils are the main OPN-producing cells. In contrast, we believe that this association may suggest that OPN might be related to the ongoing eosinophilic inflammation in SRA. This is supported by recent studies showing that OPN plays a role in the migration of eosinophils into the asthmatic airways. ${ }^{14} 25$ However, OPN had an inhibitory effect on eosinophilic inflammation in another study, while it was a significant mediator of neutrophil chemotaxis in an experimental animal model of chronic obstructive pulmonary disease. $^{15} 28$

A reasonable argument would be that the increased levels of OPN observed in SRA may be influenced by treatment with oral steroids. Steroids can increase OPN expression in cardiac myocytes and microvascular endothelial cells. ${ }^{29}$ Additionally, a region of the promoter sequence of the OPN gene contains an element that is recognised by an activated glucocorticoid receptor. ${ }^{30}$ Finally, the administration of dexamethasone for 1 week reduced the levels of OPN/protein in BAL fluid and lung tissue of ovalbumin sensitised mice. ${ }^{31}$ In order to overcome the above bias, we divided the patients with SRA on the basis of oral steroid use and also adjusted for it in the regression analysis. Both statistical analyses revealed that oral steroids did not affect OPN levels in the current study.

In patients with SRA there was a strong association between OPN and both IL-13 and TGF- $\beta 1$. All structural and immune cells in the lung can express and secrete TGF- $\beta 1 .{ }^{1}$ In addition, TGF- $\beta 1$ has been implicated in airway remodelling and has been further upregulated in severe forms of the disease. ${ }^{32}$ Previous studies have shown that OPN contributes to tissue fibrosis 
through modulation of TGF- $\beta 1 .^{33}{ }^{34}$ An altered epithelial repair phenotype of the asthmatic airway epithelium is partially mediated through the epithelial mesenchymal transition induced by TGF- $\beta 1{ }^{2}{ }^{2}$ The strong association between OPN and TGF- $\beta 1$ observed in our study supports an indirect role of OPN in the above mechanism. IL-13 has been found to be increased in sputum supernatant of patients with $\mathrm{SRA}^{35}$ and has been implicated in the cellular process of airway remodelling by activating mast cells and lung fibroblasts. ${ }^{36}$ OPN deficiency significantly decreased IL-13 levels in mice lung homogenates, ${ }^{16}{ }^{33}$ whereas the administration of OPN significantly increased the production of IL-13. ${ }^{16}$ OPN may modulate lung fibroblast activation and airway remodelling either via a direct effect on these cells or via an indirect effect that involves the expression of fibrotic mediators such as TGF- $\beta 1$ and Th2 cytokines such as IL-13. The association between OPN and cysteinyl leukotrienes in patients with SRA may be attributed to the release of cysteinyl leukotrienes by increased numbers of eosinophils which migrate into the airways through chemotaxis possibly mediated by OPN. Unfortunately, we failed to find any association between OPN and VEGF levels in patients with SRA. However, previous data suggest that OPN promotes angiogenesis and accounts, along with VEGF, for eosinophilmediated angiogenesis. ${ }^{25}$

Our study did not include bronchial biopsies, which is a limitation because we did not have the opportunity to detect the cellular source of OPN and to evaluate the subepithelial tissue which is known to contribute significantly to angiogenesis and remodelling. In a previous study subjects with severe asthma with chronic persistent obstruction had increased features of airway remodelling and Th1 and Th2 inflammation as assessed in bronchial biopsies. However, in the same study, sputum analysis was not able to identify such patients. ${ }^{37}$ This is in accordance with the lack of association between OPN levels and lung function parameters observed in our study.

In conclusion, OPN levels are significantly higher in induced sputum of patients with SRA than in those with moderate and mild asthma and healthy subjects. Since SRA is known to be characterised by an intense inflammatory and remodelling process, the correlation of OPN levels with cysteinyl leukotrienes, TGF- $\beta 1$ and IL-13 amplifies its possible role in the pathogenesis of SRA. Further studies are needed to elucidate the source and exact role of OPN in the pathogenesis of asthma.

Competing interests None.

Ethics approval This study was conducted with the approval of the ethics committees of Sotiria and Attiko Hospitals and all subjects gave their informed consent.

Provenance and peer review Not commissioned; externally peer reviewed.

\section{REFERENCES}

1. Broide DH. Immunologic and inflammatory mechanisms that drive asthma progression to remodeling. J Allergy Clin Immunol 2008;121:560-70;quiz 571-62.

2. Hackett TL, Warner SM, Stefanowicz D, et al. Induction of epithelial-mesenchymal transition in primary airway epithelial cells from patients with asthma by transforming growth factor-beta1. Am J Respir Crit Care Med 2009:180:122-33.

3. Simcock DE, Kanabar V, Clarke GW, et al. Induction of angiogenesis by airway smooth muscle from patients with asthma. Am J Respir Crit Care Med 2008:178:460-8.

4. Wenzel S. Severe asthma in adults. Am J Respir Crit Care Med 2005;172:149-60.

5. Chanez P, Wenzel SE, Anderson GP, et al. Severe asthma in adults: what are the important questions? J Allergy Clin Immunol 2007;119:1337-48.

6. Kohan M, Bader R, Puxeddu I, et al. Enhanced osteopontin expression in a murine model of allergen-induced airway remodelling. Clin Exp Allergy 2007:37:1444-54.

7. Chaulet $\mathbf{H}$, Desgranges $\mathrm{C}$, Renault MA, et al. Extracellular nucleotides induce arterial smooth muscle cell migration via osteopontin. Circ Res 2001;89:772-8.
8. Ogata T, Ueyama T, Nomura T, et al. Osteopontin is a myosphere-derived secretory molecule that promotes angiogenic progenitor cell proliferation through the phosphoinositide 3-kinase/Akt pathway. Biochem Biophys Res Commun 2007:359:341-7.

9. Ashkar S, Weber GF, Panoutsakopoulou V, et al. Eta-1 (osteopontin): an early component of type-1 (cell-mediated) immunity. Science 2000;287:860-4.

10. Wai PY, Kuo PC. The role of osteopontin in tumor metastasis. J Surg Res 2004; 121:228-41.

11. Brown LF, Berse B, Van de Water L, et al. Expression and distribution of osteopontin in human tissues: widespread association with luminal epithelial surfaces. Mol Biol Cell 1992;3:1169-80.

12. O'Regan AW, Chupp GL, Lowry JA, et al. Osteopontin is associated with T cells in sarcoid granulomas and has $T$ cell adhesive and cytokine-like properties in vitro. J Immunol 1999;162:1024-31.

13. Serlin DM, Kuang PP, Subramanian M, et al. Interleukin-1beta induces osteopontin expression in pulmonary fibroblasts. J Cell Biochem 2006;97:519-29.

14. Takahashi A, Kurokawa M, Konno $\mathrm{S}$, et al. Osteopontin is involved in migration of eosinophils in asthma. Clin Exp Allergy 2009;39:1152-9.

15. Xanthou G, Alissafi T, Semitekolou M, et al. Osteopontin has a crucial role in allergic airway disease through regulation of dendritic cell subsets. Nat Med 2007:13:570-8.

16. Simoes DC, Xanthou G, Petrochilou K, et al. Osteopontin deficiency protects agains airway remodeling and hyperresponsiveness in chronic asthma. Am J Respir Crit Care Med 2009;179:894-902.

17. Bateman ED, Hurd SS, Barnes PJ, et al. Global strategy for asthma management and prevention: GINA executive summary. Eur Respir J 2008;31:143-78.

18. American Thoracic Society (ATS). Proceedings of the ATS workshop on refractory asthma: current understanding, recommendations, and unanswered questions. Am J Respir Crit Care Med 2000;162:2341-51.

19. Kips JC, Fahy JV, Hargreave FE, et al. Methods for sputum induction and analysis of induced sputum: a method for assessing airway inflammation in asthma. Eur Respir $J$ Supp/ 1998;26:9-12S.

20. Grootendorst DC, van den Bos JW, Romeijn JJ, et al. Induced sputum in adolescents with severe stable asthma. Safety and the relationship of cell counts and eosinophil cationic protein to clinical severity. Eur Respir J 1999:13:647-53

21. Efthimiadis A, Spanevello A, Hamid 0, et al. Methods of sputum processing for cell counts, immunocytochemistry and in situ hybridisation. Eur Respir J Supp/ 2002:37:19-23s

22. American Thoracic Society. Standardization of spirometry, 1994 update. Am J Respir Crit Care Med 1995;152:1107-36.

23. Crapo R0, Casaburi R, Coates AL, et al. Guidelines for methacholine and exercise challenge testing, 1999. This official statement of the American Thoracic Society was adopted by the ATS Board of Directors, July 1999. Am J Respir Crit Care Med 2000;161:309-29.

24. Menzies D, Nair A, Lipworth BJ. Portable exhaled nitric oxide measurement: comparison with the "gold standard" technique. Chest 2007;131:410-14.

25. Puxeddu I, Berkman N, Ribatti D, et al. Osteopontin is expressed and functional in human eosinophils. Allergy 2010;65:168-74.

26. Nagasaka A, Matsue $\mathrm{H}$, Matsushima $\mathrm{H}$, et al. Osteopontin is produced by mast cells and affects lgE-mediated degranulation and migration of mast cells. Eur $\mathrm{J}$ Immunol 2008;38:489-99.

27. Kazanecki CC, Uzwiak DJ, Denhardt DT. Control of osteopontin signaling and function by post-translational phosphorylation and protein folding. J Cell Biochem 2007:102:912-24.

28. Schneider DJ, Lindsay JC, Zhou Y, et al. Adenosine and osteopontin contribute to the development of chronic obstructive pulmonary disease. FASEB J 2010;24:70-80.

29. Singh K, Balligand JL, Fischer TA, et al. Glucocorticoids increase osteopontin expression in cardiac myocytes and microvascular endothelial cells. Role in regulation of inducible nitric oxide synthase. J Biol Chem 1995;270:28471-8.

30. Wang D, Yamamoto S, Hiijya N, et al. Transcriptional regulation of the human osteopontin promoter: functional analysis and DNA-protein interactions. Oncogene 2000;19:5801-9.

31. Kurokawa M, Konno S, Matsukura S, et al. Effects of corticosteroids on osteopontin expression in a murine model of allergic asthma. Int Arch Allergy Immunol 2009;149 (Suppl 1):7-13

32. Ohno I, Nitta Y, Yamauchi K, et al. Transforming growth factor beta 1 (TGF beta 1) gene expression by eosinophils in asthmatic airway inflammation. Am J Respir Cell Mol Biol 1996:15:404-9.

33. Kohan M, Breuer $\mathrm{R}$, Berkman N. Osteopontin induces airway remodeling and lung fibroblast activation in a murine model of asthma. Am J Respir Cell Mol Biol 2009:41:290-6.

34. Denhardt DT, Noda M, O'Regan AW, et al. Osteopontin as a means to cope with environmental insults: regulation of inflammation, tissue remodeling, and cell survival. J Clin Invest 2001;107:1055-61.

35. Saha SK, Berry MA, Parker D, et al. Increased sputum and bronchial biopsy IL-13 expression in severe asthma. J Allergy Clin Immunol 2008;121:685-91.

36. Kasaian MT, Miller DK. IL-13 as a therapeutic target for respiratory disease. Biochem Pharmacol 2008;76:147-55.

37. Kaminska M, Foley S, Maghni K, et al. Airway remodeling in subjects with severe asthma with or without chronic persistent aifflow obstruction. J Allergy Clin Immunol 2009; 124:45-51, e1-4 